\title{
Farelo de trigo na alimentação de poedeiras semipesadas na fase de recria
}

\section{Daniel de Magalhães Araujo ${ }^{1^{*}}$, José Humberto Vilar da Silva ${ }^{2}$, José Anchieta de Araujo ${ }^{3}$, Elisanie Neiva Magalhães Teixeira ${ }^{1}$, José Jordão Filho ${ }^{4}$, Marcelo Luís Gomes Ribeiro ${ }^{4}$}

\author{
1 Pós-graduação em Zootecnia pelo PPGZ/CCA/UFPB, Areia - PB. \\ 2 DAP/CFT/UFPB, Bananeiras - PB e PPGZ/CCA/UFPB, Areia - PB. \\ ${ }^{3}$ Licenciatura em Ciências Agrárias - Bolsista PIBIC - CNPq/UFPB. \\ ${ }^{4}$ Programa de Doutorado Integrado em Zootecnia - PDIZ/CCA/UFPB - Areia - PB.
}

RESUMO - O estudo foi conduzido com o objetivo de avaliar os efeitos da inclusão de farelo de trigo (FT) na ração sobre o desempenho de frangas semipesadas nas fases de recria 1 ( 7 a 14 semanas de idade) e recria 2 (15 a 19 semanasde idade) e seu efeito residual durante a fase inicial de produção de ovos. Foram utilizadas 160 frangas Lohmann Brown distribuídas em delineamento inteiramente casualizado, com quatro níveis de FT na ração: 0 (controle), 10, 20 e 30\%, que resultaram em quatro tratamentos, com cinco repetições de oito aves na fase de recria 1. Ao completarem 14 semanas, as aves foram transferidas para gaiolas de arame galvanizado, redistribuídas em seis repetições de seis aves. Utilizaram-se 144 aves e descartaram-se, aleatoriamente, quatro aves por tratamento, constituindo a fase de recria 2. A adição de FT diminuiu linearmente o peso vivo final e o ganho de peso, resultando em reduções de 1,15 e 0,03 g, respectivamente, para cada $1 \%$ de inclusão de FT na ração. O consumo de água aumentou de forma quadrática e cresceu, em valores absolutos, com o aumento de 0 a $30 \%$ de farelo de trigo. A cada aumento de $1 \%$ de FT na ração, a idade das aves ao primeiro ovo elevou aproximadamente 0,6 dia e o peso do ovo em 0,22 g. A inclusão de farelo de trigo na ração reduz a taxa de crescimento de frangas, atrasa o início da postura, mas melhora o peso inicial dos ovos em relação a dietas à base de milho e de farelo de soja.

Palavras-chave: alimento alternativo, desempenho, idade ao primeiro ovo

\section{Wheat bran in growing phase laying hens feeding}

\begin{abstract}
This study aimed to evaluate the effect of the inclusion of the wheat bran (WB) in the ration on egg brown chicken (Lohmann Brown) performance in the growing phase 1 (7 to 19 week of age) and growing phase 2 (15 to 19 week of age) and its residual effects on initial egg production. One hundred-sixty chickens were allotted to a completely randomized design with four level of WB in the ration: 0 (control), 10, 20 and 30\%, that resulted in four treatments, with five replicates of eight birds in the growing phase 1 . At the $14^{\text {th }}$ week, the birds were transferred to galvanized wire cages and reallocated in six replicates of six birds each. A total of 144 birds were used and, randomly, four birds per treatment were discarding per treatment, constituting the growing phase 2. The addition of the WB linearly decreased the final body weight and the weight gain, resulting in decreasing of $1.15 \mathrm{~g}$ and $0.0 \mathrm{3g}$, respectively for each $1 \%$ of WB inclusion in the ration. Water intake show a quadratic effect and increased in absolute values with the addition of WB from 0 to $30 \%$. The birds age at the first egg production and egg weight increased 0.6 day and $0.22 \mathrm{~g}$, respectively for each $1 \%$ of WB in the ration. The inclusion of WB reduces chickens growth rate, delays posture starting and improves egg initial weight when compared to corn and soybean meal based diets.
\end{abstract}

Key Words: age at first egg production, alternative feedstuff, performance

\section{Introdução}

O uso de resíduos agroindustriais na alimentação animal, além de agregar valor a esses subprodutos e reduzir a potencial poluição ambiental, diminui a competição por alimentos entre a população humana e a produção de animais monogástricos, pela simples redução do uso do milho, do farelo de soja e de outros grãos na alimentação animal e pela produção de ovos e carne, fontes de proteína de alta qualidade a partir de resíduos não utilizados na alimentação humana.

O farelo de trigo é o principal e mais abundante subproduto da moenda de grãos e consiste em um recurso alimentar renovável e pouco explorado (Yuan et al., 2005; 
Beaugrand et al., 2004), principalmente em dietas para aves. É formado por tecidos botânicos distintos, exteriores ao núcleo do trigo, como o pericarpo (película que recobre o grão), a testa (película que recobre a semente), a camada hialina e a aleurona, partes extenas do endosperma (Evers \& Millar, 2002). O endosperma é composto de diferentes tipos de células, em sua maioria de paredes celulares grossas e difíceis de quebrar. Entretanto, o processo de moenda permite o rompimento dessas paredes, liberando micronutrientes considerados anticancerígenos (como o selênio e o ácido fólico ou fitoquímicos), flavonóides e ácido fítico (Helsby et al., 2000).

O farelo de trigo apresenta boa concentração de proteína (15,52\%, com base na matéria natural, de acordo com Rostagno et al., 2005), entretanto, sua adição na dieta de aves é limitada pela alta concentração de fibra (9,66\%, com base na MS, de acordo com Rostagno et al., 2005). De acordo com Maes et al. (2004), os principais polissacarídeos não-amídicos (PNA) presentes neste subproduto são as arabinoxilanas (36,5\%), mas contêm também celulose (11\%), lignina (3 a 10\%) e ácidos urônicos (3 a 6\%).

As arabinoxilanas do farelo de trigo apresentam conhecida propriedade de reter água e promover a viscosidade em soluções (Schooneveld-Bergmans et al., 1999). O aumento da viscosidade da digesta em nível intestinal pode alterar a morfologia e a fisiologia entérica, modificando a taxa de trânsito e desregulando a função hormonal, em virtude de uma taxa variada de absorção de nutrientes. A digestibilidade da proteína pode ser reduzida pelas arabinoxilanas do trigo, pela inibição e/ou pelo desarranjo da digestão da proteína ou pela redução da absorção de aminoácidos. Também pode resultar em aumento na secreção de proteínas endógenas, derivadas das secreções e de células intestinais (Bedford \& Partridge, 2001).

A fermentação anaeróbica dos PNA do farelo de trigo produz ácidos graxos voláteis de cadeia curta (acetato, propionato e butirato), sobretudo o butirato, mantendo seus níveis por mais tempo ao longo do lúmen intestinal. Uma vez que a maior concentração e permanência deste ácido no lúmen intestinal está correlacionada ao aumento da apoptose de células inflamatórias (Hollmann \& Lindhauer, 2005; Scheppach et al., 2004), a adição de farelo de trigo na ração pode ser benéfica à saúde intestinal.

Este trabalho foi realizado para avaliar os efeitos da inclusão de farelo de trigo em rações para frangas semipesadas na fase de recria e os possíveis efeitos residuais dessas rações sobre a fase inicial de produção de ovos.

\section{Material e Métodos}

O experimento foi conduzido no Laboratório Avícola do Centro de Formação de Tecnólogos (CFT), Campus III da Universidade Federal da Paraíba, UFPB, em Bananeiras, na microrregião do Brejo Paraibano. Foram utilizadas 160 poedeiras semipesadas da linhagem Lohmann Brown com 7 semanas de idade e de 509,21 $\pm 2,71 \mathrm{~g}$ de peso vivo (PV).

O delineamento experimental utilizado foi o inteiramente ao acaso, constituído da inclusão de 0, 10, 20 e 30\% de farelo de trigo (FT) na ração. No período de 7 a 14 semanas de idade, as aves foram alojadas em boxes de $1,5 \mathrm{~m}^{2}$, com piso coberto com cama de bagaço de cana e tela à prova de pássaros e de possíveis predadores, com oito aves por boxe e cinco repetições por tratamento. Ao completarem 14 semanas, as aves foram transferidas para gaiolas de arame galvanizado (5 aves/gaiola), mantendo-se os grupos correspondentes. Das dez aves de cada tratamento, foi constituída aleatoriamente a sexta repetição, enquanto as quatro aves restantes foram descartadas.

O galpão experimental possuía cobertura de telhas de barro em duas águas, pé-direito de 1,8 m de altura, duas fileiras de gaiolas sobrepostas e um corredor de $1 \mathrm{~m}$ de largura entre as fileiras de gaiolas, além de orientação Leste-Oeste. Cada gaiola de arame galvanizado media $25 \times 45 \times 40 \mathrm{~cm}$. As temperaturas máximas e mínimas registradas foram 31,51 e $21,31^{\circ} \mathrm{C}$, enquanto a umidade relativa do ar foi 95 e $44 \%$, respectivamente, verificada pela manhã (8 h) e à tarde (16 h).

As rações fornecidas nas fases de recria 1 (7a a $14^{\text {a }}$ semana de idade) e recria 2 (15a a 19 a semana de idade), isoenergéticas (2.850 kcal/kg) e isoprotéicas (15,30\% PB), foram formuladas segundo Rostagno et al. (2000) para atender às exigências nutricionais das aves (Tabela 1). Para avaliar os efeitos residuais da inclusão de farelo de trigo nas dietas no período de 7 a 19 semanas de idade sobre o início da produção de ovos, as aves foram alimentadas a partir da $20^{\text {a }}$ semana com uma dieta convencional para a fase de postura (2.700 kcal/kg, 15,95\% PB, 4,1\% de cálcio e 0,38\% de fósforo disponível), isenta de farelo de trigo, também formulada de acordo com Rostagno et al. (2000). As aves continuaram sendo observadas por dois períodos de 28 dias de produção de ovos. As aves receberam água e ração à vontade durante todo o período experimental. Semanalmente, até as aves atingirem aproximadamente $50 \%$ de produção, foram pesadas todas as aves, as sobras de ração e os ovos produzidos, por parcela.

As variáveis estudadas na fase de recria 1 foram peso vivo final (PVF), ganho de peso (GP), consumo de água (CAG), 
Tabela 1 - Composição das rações experimentais nas fases de recria 1 e $2^{1}$

\begin{tabular}{|c|c|c|c|c|}
\hline \multirow[t]{2}{*}{ Ingrediente } & \multicolumn{4}{|c|}{ Nível de farelo de trigo (\%) } \\
\hline & 0 & 10 & 20 & 30 \\
\hline Milho & 71,008 & 67,508 & 61,485 & 50,907 \\
\hline Farelo de soja & 20,138 & 17,012 & 14,377 & 12,632 \\
\hline Farelo de trigo & 0,000 & 10,000 & 20,000 & 30,000 \\
\hline Calcário & 0,894 & 0,960 & 1,019 & 1,067 \\
\hline Fosfato bicálcio & 1,556 & 1,447 & 1,343 & 1,250 \\
\hline Óleo vegetal & 0,000 & 0,000 & 0,841 & 3,200 \\
\hline Suplemento vitamínico ${ }^{2}$ & 0,080 & 0,080 & 0,080 & 0,080 \\
\hline Suplemento mineral ${ }^{3}$ & 0,050 & 0,050 & 0,050 & 0,050 \\
\hline Cloreto de colina & 0,100 & 0,100 & 0,100 & 0,100 \\
\hline Antioxidante 4 & 0,010 & 0,010 & 0,010 & 0,010 \\
\hline Sal & 0,099 & 0,119 & 0,146 & 0,177 \\
\hline Bicarbonato de sódio & 0,318 & 0,289 & 0,239 & 0,197 \\
\hline Coccidiostático & 0,040 & 0,040 & 0,040 & 0,040 \\
\hline Promotor de crescimento & 0,010 & 0,010 & 0,010 & 0,010 \\
\hline Cloreto de potássio & 0,109 & 0,076 & 0,040 & 0,000 \\
\hline Inerte $^{5}$ & 5,524 & 2,155 & 0,002 & 0,000 \\
\hline L-Lys.HCl & 0,019 & 0,068 & 0,108 & 0,131 \\
\hline DL-Met & 0,045 & 0,052 & 0,062 & 0,078 \\
\hline L-Thr & 0,000 & 0,024 & 0,048 & 0,071 \\
\hline \multicolumn{5}{|c|}{ Composição nutricional calculada } \\
\hline $\mathrm{PB}$ & 15,300 & 15,300 & 15,300 & 15,300 \\
\hline EM (kcal/kg) & 2.850 & 2.850 & 2.850 & 2.850 \\
\hline Fibra bruta & 2,535 & 3,137 & 3,781 & 4,424 \\
\hline Met digestível & 0,279 & 0,288 & 0,280 & 0,277 \\
\hline Met + Cys digestível & 0,500 & 0,500 & 0,500 & 0,500 \\
\hline Lys digestível & 0,668 & 0,668 & 0,668 & 0,668 \\
\hline Thr digestível & 0,510 & 0,510 & 0,510 & 0,512 \\
\hline Trp digestível & 0,150 & 0,154 & 0,158 & 0,159 \\
\hline $\mathrm{Ca}(\%)$ & 0,815 & 0,815 & 0,815 & 0,815 \\
\hline $\mathrm{P}$ disponível & 0,383 & 0,383 & 0,383 & 0,383 \\
\hline $\mathrm{Na}(\%)$ & 0,157 & 0,157 & 0,160 & 0,160 \\
\hline $\mathrm{K}$ & 0,641 & 0,640 & 0,640 & 0,640 \\
\hline $\mathrm{Cl}(\%)$ & 0,148 & 0,148 & 0,148 & 0,148 \\
\hline
\end{tabular}

${ }^{1}$ Recomendações de Rostagno et al. (2000).

${ }^{2}$ Composição por kg do produto: vit. A - $10.000 .000 \mathrm{UI}$; vit. $\mathrm{D}_{3}-2.500 .000 \mathrm{UI}$; vit. E - 6.000 UI; vit. K - 1,6 g; vit. $B_{12}-11.000$ mcg; niacina - 2,5 g; ácido fólico - 0,4 g; ácido pantotênico - $10 \mathrm{~g}$; Se - 0,3 g; veículo q.s.p.

${ }^{3}$ Micromin - suplemento mineral para aves. Composição por $\mathrm{kg}$ do produto: Mn - 150 g; Zn - 100 g; Fe - 100 g; Cu - 16 g; I - 1,5 g; veículo (vehicle) q.s.p.

${ }^{4}$ Antioxidante $=$ BHT (Butil-hidroxi-tolueno).

5 Inerte: areia lavada.

D = aminoácido digestível.

consumo de ração (CR), conversão alimentar (CA) e relação entre CAG e CR (CAG/CR). Na fase de recria 2, todas as variáveis anteriores foram avaliadas, com exceção do consumo de água, que não foi medido, e da relação CAG/CR. Foram avaliados ainda a idade das aves ao primeiro ovo (DIA) e o peso inicial do ovo (PIO). Na fase de produção, foram avaliados o peso vivo inicial (PVI), o consumo de ração (CR), a produção (PR), o peso do ovo (PO), a massa de ovos (MO), a conversão por massa (CMO), a conversão por dúzia de ovos (CDZ) e a gravidade específica (GE) dos ovos.

A coleta de dados da fase de produção foi iniciada quando as aves atingiram $50 \%$ de produção, ou seja, na 24a semana. Portanto, o peso vivo final das aves na fase de recria 2 (da 15a à 19aㅡ semana) difere do peso vivo inicial da fase de produção. A produção de ovos foi obtida em porcentagem/ave/dia. O peso dos ovos foi o valor médio do peso dos ovos produzidos nos últimos cinco dias de cada um dos dois períodos da fase de produção. A massa de ovos representou o produto da porcentagem de ovos produzidos pelo peso médio dos ovos, enquanto a conversão alimentar por massa de ovos foi expressa em quilos de ração consumida por quilo de massa de ovos produzida e a conversão alimentar por dúzia de ovos correspondeu à relação entre a quantidade de ração consumida $(\mathrm{kg})$ por dúzia de ovos produzida. A gravidade específica foi determinada pelo método da flutuação dos ovos, em 15 soluções salinas, com variação da densidade em 0,0025 unidades, iniciando por 1,0625 até 1,100 . Para isso, foram utilizados 15 baldes com capacidade de $50 \mathrm{~L}$, um densímetro de petróleo com escala de 1,050 a 1,100, uma cesta de plástico (balde vazado), água e sal comum, sempre nos últimos três dias de cada fase experimental. As aves mortas e as sobras das dietas foram consideradas para ajustar o consumo, a produção de ovos e as conversões alimentares.

As análises estatísticas foram realizadas utilizando-se o programa SAEG (Euclydes, 1983). Após a análise de variância, o efeito dos níveis de farelo de trigo sobre as variáveis foram avaliados pelo teste Student-Newman-Keuls $(\mathrm{P} \leq 0,05)$. Posteriormente, a soma dos quadrados dos efeitos do farelo de trigo foi decomposta nos efeitos linear, quadrático e cúbico. Na escolha dos modelos de regressão, foram considerados o nível de significância, o coeficiente de determinação $\left(\mathrm{R}^{2}\right)$ e a resposta biológica das aves.

\section{Resultados e Discussão}

Na fase de recria 1, o consumo de ração, a conversão alimentar e a relação entre consumo de água e de ração não foram afetados $(\mathrm{P}>0,05)$ pela inclusão do farelo de trigo na ração (Tabela 2).

A adição de farelo de trigo na ração promoveu redução linear $(\mathrm{P}<0,05)$ do peso vivo final, conforme a equação $\hat{\mathrm{Y}}=900,271-1,14682 \mathrm{X}\left(\mathrm{r}^{2}=0,91\right)$, e do ganho de peso, conforme a equação $\hat{Y}=15,1759-0,0293103 X\left(r^{2}=0,74\right)$. O peso vivo final diminuiu $1,14 \mathrm{~g}$ à medida que se aumentou em $1 \%$ o nível de farelo de trigo na ração, enquanto o ganho de peso reduziu aproximadamente 0,03 g para o mesmo aumento na quantidade de farelo de trigo, de modo que as aves mais leves ao final do período experimental foram aquelas alimentadas com as dietas com os maiores níveis de farelo de trigo. É provável que o aumento de $40 \%$ no teor de fibra bruta da ração basal para a ração com $30 \%$ de farelo de trigo tenha afetado negativamente a utilização dos 
nutrientes, uma vez que a fibra atua como barreira, impedindo que as proteases tenham acesso aos locais nas células vegetais onde estão depositados os aminoácidos. Um aumento na secreção de proteínas endógenas, derivadas das secreções e de células intestinais também pode ser uma das explicações (Bedford \& Partridge, 2001). A abrasividade da fibra pode causar descamação do epitélio intestinal e promover turnover celular acelerado deste tecido.

A inclusão de farelo de trigo na ração teve efeito quadrático $(\mathrm{P}<0,01)$ sobre o consumo de água, que decresceu até o ponto de 13,74\% de inclusão de farelo de trigo, quando aumentou novamente atingindo valor máximo com 30\% de farelo de trigo: $\hat{Y}=89,9791-1,56936 X+0,0570853 X^{2}$ $\left(r^{2}=0,93\right)$. Os dados obtidos neste trabalho corroboram os relatos de Cunningham (2004) de que a atividade osmótica aumenta durante a digestão e que, com a continuação do proceso, as moléculas de açúcar são absorvidas, e conseqüentemente a água, passivamente pelo epitélio, retornando ao sistema vascular sangüíneo. No caso deste estudo, no entanto, as fibras que não são digeridas ou absorvidas quando o farelo de trigo é adicionado em níveis superiores a $13,74 \%$ podem não ter criado ambiente de menor pressão osmótica no lúmen intestinal, necessário para a reabsorção desta água. Então, parte da água pode ter sido retida, principalmente pelas fibras solúveis, e posteriormente excretada.

Na fase de recria 2, o peso vivo final ( $\hat{Y}=1438,51$ 6,54861X; $\mathrm{r}^{2}=0,89$ ), o consumo de ração ( $\hat{Y}=79,6825$ $\left.0,716518 X ; r^{2}=0,97\right)$ e o ganho de peso $(\hat{Y}=12,829$ - $\left.0,265102 X ; r^{2}=0,90\right)$ foram afetados $(P<0,01)$ negativamente pela inclusão de farelo de trigo nas rações (Tabela 3). O peso vivo final foi $6,5 \mathrm{~g}$ menor, o consumo de ração diminuiu $0,71 \mathrm{~g}$ e o ganho de peso foi $0,26 \mathrm{~g}$ menor para cada aumento de 1\% na inclusão de farelo de trigo nas dietas.

A conversão alimentar ( $\hat{Y}=5,83317+0,17978 X$; $\mathrm{r}^{2}=0,81$ ), que não foi afetada nas primeiras sete semanas de avaliação (recria 1), nesta fase, com a redução no ganho de peso, piorou $(\mathrm{P}<0,01)$ em $46 \%$, aumentando de 6,17 para 11,39 com o aumento dos níveis de farelo de trigo de 0 a $30 \%$.

Verificou-se na fase de recria 2 forte correlação positiva entre o nível de farelo de trigo na ração e a idade das aves ao primeiro ovo $(\mathrm{P}<0,0001 ; \mathrm{R}=0,71)$; entre o nível de farelo de trigo e o peso inicial do ovo $(\mathrm{P}<0,0099 ; \mathrm{R}=0,47)$ e entre a idade da ave ao primeiro ovo e o peso inicial do ovo $(\mathrm{P}<0,01 ; \mathrm{R}=0,70)$ (Tabela 4$)$. A cada $1 \%$ de inclusão de farelo de trigo na ração, a idade das aves ao primeiro ovo aumentou em $0,6 \operatorname{dia}\left(\hat{\mathrm{Y}}=129,7+0,62 \mathrm{X} ; \mathrm{r}^{2}=1,0\right)$ e o peso do ovo em 0,22 g ( $\left.\hat{Y}=37,9778+0,222283 X ; r^{2}=0,84\right)$. Como o peso dos ovos é diretamente proporcional ao peso da poedeira, o efeito do farelo de trigo de aumentar o peso inicial do ovo está relacionado ao maior peso das aves à postura. O farelo de trigo pode ter útil em programas de restrição alimentar para frangas de crescimento precoce ou para matrizes pesadas.

O aumento dos níveis de farelo de trigo na ração fornecida às poedeiras de 7 a 19 semanas de idade não afetou $(\mathrm{P}>0,05)$ o peso vivo inicial, o consumo de ração, o peso do ovo, a

Tabela 2 - Desempenho, consumo de água e relação entre consumo de água e de ração de poedeiras alimentadas com rações contendo farelo de trigo na fase de recria 1

\begin{tabular}{|c|c|c|c|c|c|c|}
\hline & \multicolumn{4}{|c|}{ Nível de farelo de trigo (\%) } & \multirow[t]{2}{*}{ Efeito } & \multirow[t]{2}{*}{$\mathrm{CV} \%$} \\
\hline & 0 & 10 & 20 & 30 & & \\
\hline Peso vivo final, kg & 0,90 & 0,88 & 0,87 & 0,87 & $\mathrm{~L}^{*}$ & 2,66 \\
\hline Consumo de ração (CR), g/ave/dia & 64,35 & 65,13 & 59,51 & 61,58 & ns & 9,94 \\
\hline Ganho de peso, g/ave/dia & 15,26 & 14,91 & 14,27 & 14,50 & $\mathrm{~L}^{* *}$ & 3,92 \\
\hline Conversão alimentar & 4,21 & 4,36 & 4,17 & 4,24 & ns & 9,30 \\
\hline Consumo de água (CAG), g/ave/dia & $90,72 \mathrm{ab}$ & $77,76 \mathrm{~b}$ & $83,66 \mathrm{ab}$ & $93,53 a$ & $\mathrm{Q}^{* *}$ & 10,06 \\
\hline Relação CAG/CR & 1,41 & 1,19 & 1,40 & 1,51 & ns & 15,05 \\
\hline
\end{tabular}

Médias nas colunas seguidas de letras minúsculas distintas são diferentes $(P<0,05)$ pelo teste SNK.

$\mathrm{L}=$ efeito linear. $\mathrm{Q}=$ efeito quadrático. $\mathrm{ns}=$ não-significativo.

${ }^{*}(\mathrm{P}<0,05) ;{ }^{* *}(\mathrm{P}<0,01)$

Tabela 3 - Desempenho de poedeiras alimentadas com dietas contendo farelo de trigo na fase de recria 2

\begin{tabular}{|c|c|c|c|c|c|c|}
\hline & \multicolumn{4}{|c|}{ Nível de farelo de trigo (\%) } & \multirow[t]{2}{*}{ Efeito } & \multirow[t]{2}{*}{$\mathrm{CV} \%$} \\
\hline & 0 & 10 & 20 & 30 & & \\
\hline Peso vivo final, kg & $1,44 \mathrm{a}$ & $1,37 b$ & $1,29 c$ & $1,25 d$ & $\mathrm{~L} * *$ & 1,92 \\
\hline Consumo de ração, g/ave/dia & $79,96 a$ & $72,49 b$ & $64,60 c$ & $58,70 \mathrm{~d}$ & $\mathrm{~L} * *$ & 2,20 \\
\hline Ganho de peso, g/ave/dia & $12,94 \mathrm{a}$ & $10,22 b$ & 7,10c & $5,15 d$ & $\mathrm{~L} * *$ & 11,55 \\
\hline Conversão alimentar & $6,17 \mathrm{c}$ & $7,09 \mathrm{c}$ & $9,01 b$ & $11,39 a$ & $\mathrm{~L}^{* *}$ & 11,41 \\
\hline
\end{tabular}

Médias nas colunas seguidas de letras minúsculas distintas são diferentes $(P<0,05)$ pelo teste SNK.

$\mathrm{L}=$ efeito linear. ${ }^{\star *}(\mathrm{P}<0,01)$ 
Tabela 4 - Idade ao primeiro ovo e peso inicial do ovo de poedeiras alimentadas com dietas contendo farelo de trigo na fase de recria 2

\begin{tabular}{|c|c|c|c|c|c|c|}
\hline & \multicolumn{4}{|c|}{ Nível de farelo de trigo (\%) } & Efeito & CV\% \\
\hline Idade, dias & 130 & 136 & 143 & 148 & $\mathrm{~L}^{* *}$ & 5,41 \\
\hline
\end{tabular}

$\mathrm{FT}=$ farelo de trigo, Idade $=$ Idade ao primeiro ovo.

$\mathrm{L}=$ efeito linear.

$* *(P<0,01)$.

Tabela 5 - Desempenho e outras características produtivas de poedeiras alimentadas com dietas contendo farelo de trigo na fase de recria 2

\begin{tabular}{|c|c|c|c|c|c|c|}
\hline & \multicolumn{4}{|c|}{ Nível de farelo de trigo (\%) } & Efeito & $\mathrm{CV} \%$ \\
\hline Peso vivo inicial, kg & 1,71 & 1,65 & 1,65 & 1,66 & ns & 5,06 \\
\hline Produção de ovos, \% & $85,50 \mathrm{a}$ & $80,70 \mathrm{ab}$ & 79,90ab & $77,20 \mathrm{~b}$ & $\mathrm{~L}^{*}$ & 5,37 \\
\hline Peso do ovo, g & 57,23 & 56,64 & 56,00 & 58,40 & ns & 5,76 \\
\hline Massa do ovo, g & $48,97 \mathrm{a}$ & $45,67 a b$ & 43,17b & $46,54 a b$ & $\mathrm{Q}^{*}$ & 6,69 \\
\hline Gravidade específica, $\mathrm{g} / \mathrm{cm}^{3}$ & 1,08 & 1,08 & 1,08 & 1,08 & ns & 0,15 \\
\hline
\end{tabular}

Médias nas colunas, seguidas de letras minúsculas distintas são diferentes pelo teste SNK $(P<0,05)$. L = efeito Linear. $Q=$ efeito quadrático. ns = nãosignificativo.

${ }^{*}(P<0,05) ;{ }^{* *}(P<0,01)$.

conversão por dúzia de ovos e a gravidade específica da casca dos ovos na fase de produção (Tabela 5).

Houve efeito residual $(\mathrm{P}<0,05)$ da ração contendo farelo de trigo sobre a produção de ovos, a massa de ovos e a conversão por massa de ovos. A produção ( $\hat{Y}=0,838661$ $\left.0,00204055 \mathrm{X} ; \mathrm{r}^{2}=0,58\right)$ foi afetada $(\mathrm{P}<0,05)$ de forma linear, uma vez que as aves alimentadas com as dietas com os maiores níveis de farelo de trigo produziram menos ovos. A massa de ovos ( $\hat{Y}=49,229-0,599744 X+0,0166926 X^{2}$; $\left.\mathrm{r}^{2}=0,92\right)$ e a conversão por massa de ovos ( $\hat{\mathrm{Y}}=3,17548+$ $\left.0,0280053 \mathrm{X}-0,000821082 \mathrm{X}^{2} ; \mathrm{r}^{2}=0,41\right)$ foram afetadas $(\mathrm{P}<0,05)$ de forma quadrática pelos níveis de farelo de trigo na ração.

Braga et al. (2005) avaliaram o desempenho de poedeiras em produção alimentadas com rações contendo níveis crescentes de farelo de coco (0, 5, 10, 15 e 20\%) e observaram que o fornecimento desse subproduto aumentou o percentual de fibra bruta da dieta de 2,08 para 4,5\%, o que resultou em valores próximos aos observados neste estudo, no qual as aves foram alimentadas com rações com 2,53 a $4,42 \%$ de fibra ( 0 a $30 \%$ de farelo de trigo, respectivamente) apenas nas fases de recria $1 \mathrm{e} 2$. Esses autores afirmaram que a produção e a massa de ovos foram reduzidas em valores absolutos, mas não houve diferença estatística para essas variáveis. Afirmaram ainda que apenas o consumo de ração pelas aves alimentadas com as dietas com $20 \%$ de farelo de coco foi estatisticamente reduzido, no entanto, deve-se ter cautela na utilização de ingredientes que reduzem o consumo, ainda que não afetem outras variáveis de desempenho.

\section{Conclusões}

A inclusão de farelo de trigo na ração de recria reduz a taxa de crescimento de frangas e atrasa o início da postura, o que promove aumento no peso inicial dos ovos em relação a dietas à base de milho e de farelo de soja. A produção de ovos nos primeiros 56 dias da fase de produção reduz com a inclusão de farelo de trigo nas rações para aves de reposição no período de 7 a 19 semanas de idade.

\section{Literatura Citada}

BEDFORD, M.R.; PARTRIDGE, G.G. Enzymes in farm animal nutrition. Marlborough: CABI Publishing/Finnfeeds International, 2001. p.432.

BRAGA, C.V.P.; FUENTES, M.F.F.; FREITAS, E.R. et al. Efeito da Inclusão do Farelo de Coco em Rações para Poedeiras Comerciais. Revista Brasileira de Zootecnia, v.34, n.1, p.76-80, 2005.

BEAUGRAND, J.; CRÔNIER, D.; DEBEIRE, P. et al. Arabinoxylan and hydroxycinnamate content of wheat bran in relation to endoxylanase susceptibility. Journal of Cereal Science, v.40, p.223-230, 2004.

CUNNINGHAM, J.G. Tratado de fisiologia veterinária. 3.ed. Rio de Janeiro: Guanabara Koogan, 2004. 577p.

EVERS, T.; MILLAR, S. Cereal grain structure and development: some implications for quality. Journal of Cereal Science, v.36, p.261-284, 2002. 
EUCLYDES, R.F. SAEG (Sistema de Análises Estatísticas e Genéticas). Versão 5.0. Viçosa, MG: Universidade Federal de Viçosa, 1983. 69p. (Manual do usuário).

HELSBY, N.A.; ZHUA, S.; PEARSON, AMIRA E. Antimutagenic effects of wheat bran diet through modification of xenobiotic metabolising enzymes. Mutation Research, v.454, p.77-88, 2000.

HOLLMANN, J.; LINDHAUER, M.G. Pilot-scale isolation of glucuronoarabinoxylans from wheat bran. Carbohydrate Polymers, v.59, p.225-230, 2005.

YUAN, X.; WANG, J.; YAO, H. Antioxidant activity of feruloylated oligosaccharides from wheat bran. Food Chemistry, v.90, p.759-764, 2005.

MAES, C.; VANGENEUGDEN, B.; DELCOUR, J.A. Relative activity of two endoxylanases towards water-unextractable arabinoxylans in wheat bran. Journal of Cereal Science, v.39, p.181-186, 2004.

ROSTAGNO, H.S.; ALBINO, L.F.T.; DONZELE, J.L. et al. Tabelas brasileiras para suínos e aves: composição de alimentos e exigências nutricionais. Viçosa, MG: Universidade Federal de Viçosa, 2000. 141p.

ROSTAGNO, H.S.; ALBINO, L.F.T.; DONZELE, J.L. et al. Tabelas brasileiras para suínos e aves: composição de alimentos e exigências nutricionais. 2.ed. Viçosa, MG: Universidade Federal de Viçosa, 2005. 186p.

SCHEPPACH, W.; LUEHRS, H.; MELCHER, R. et al. Antiinflammatory and anticarcinogenic effects of dietary fibre. Clinical Nutrition Supplements, v.1, p.51-58, 2004.

SCHOONEVELD-BERGMANS, M.E.F.; BELDMAN, G.; VORAGEN, A.G.J. Structural features of (glucurono)arabinoxylans extracted from wheat bran by barium hydroxide. Journal of Cereal Science, v.29, p.63-75, 1999.

SILVA, J.H.V. Relatório técnico do uso de subprodutos do urucum na ração de aves. Bananeiras: DAP/UFPB, 2003a. $5 p$.

SILVA, J.H.V. Produção científica em nutrição de aves. Contribuição da UFPB nos últimos cinco anos. Bananeiras: DAP/UFPB, 2003b. 31p. 